\title{
UCRL-CONF-209414
}

LAWRENCE LIVERMORE N A T IO N A L LABORATORY

\section{Nuclear Design Considerations for Z-IFE Chambers}

W. R. Meier, R. C. Schmitt, R. P. Abbott, J. F. Latkowski, S. Reyes

February 3, 2005

Seventh International Symposium on Fusion Nuclear Technology (ISFNT-7)

Tokyo, Japan

May 22, 2005 through May 27, 2005 
This document was prepared as an account of work sponsored by an agency of the United States Government. Neither the United States Government nor the University of California nor any of their employees, makes any warranty, express or implied, or assumes any legal liability or responsibility for the accuracy, completeness, or usefulness of any information, apparatus, product, or process disclosed, or represents that its use would not infringe privately owned rights. Reference herein to any specific commercial product, process, or service by trade name, trademark, manufacturer, or otherwise, does not necessarily constitute or imply its endorsement, recommendation, or favoring by the United States Government or the University of California. The views and opinions of authors expressed herein do not necessarily state or reflect those of the United States Government or the University of California, and shall not be used for advertising or product endorsement purposes. 


\title{
Nuclear Design Considerations for Z-IFE Chambers
}

\author{
W.R. Meier ${ }^{* a}$, R.C. Schmitt ${ }^{b}$, R.P. Abbott ${ }^{\mathrm{a}}$, J.F. Latkowski ${ }^{\mathrm{a}}$, S. Reyes ${ }^{\mathrm{a}}$ \\ ${ }^{a}$ Lawrence Livermore National Laboratory, P.O. Box 808, L-641, Livermore, CA 94551 USA \\ ${ }^{b}$ Bettis Atomic Power Laboratory, Pittsburgh, PA 15203 USA
}

\begin{abstract}
Z-pinch driven IFE (Z-IFE) requires the design of a repetitive target insertion system that allows coupling of the pulsed power to the target with adequate standoff, and a chamber that can withstand blast and radiation effects from large yield targets. The present strategy for Z-IFE is to use high yield targets ( 2-3 GJ/shot), low repetition rate per chamber $(\sim 0.1 \mathrm{~Hz})$, and 10 chambers per power plant. In this study, we propose an alternative power plant configuration that uses very high yield targets (20 GJ/shot) in a single chamber operating at $0.1 \mathrm{~Hz}$. A thick-liquid-wall chamber is proposed to absorb the target emission (x-rays, debris and neutrons) and mitigate the blast effects on the chamber wall. The target is attached to the end of a conical shaped Recyclable Transmission Line (RTL) made from a solid coolant (e.g., frozen flibe), or a material that is easily separable from the coolant (e.g., steel). The RTL/target assembly is inserted through a single opening at the top of the chamber for each shot. This study looks at the RTL material choice from a safety and environmental point of view. Materials were assessed according to waste disposal rating (WDR) and contact dose rate (CDR). Neutronics calculations, using the TART2002 Monte Carlo code from Lawrence Livermore National Laboratory (LLNL), were performed for the RTL and Z-IFE chamber, and key results reported here.
\end{abstract}

Keywords: IFE, z-pinch, fusion chamber, neutronics

*Corresponding author. Tel: +1-925-422-8536

Fax: +1-925-424-6401

E-mail address: meier5@llnl.gov

* This work performed under the auspices of the U.S. Department of Energy by University of California, Lawrence Livermore National Laboratory under contract No. W-7405-Eng-48. 


\section{Introduction}

The Z-pinch Inertial Fusion Energy (Z-IFE) concept uses pulsed power to ignite an indirect-drive target that is attached to the end of a conical shaped Recyclable Transmission Line (RTL) [1]. The RTL/target assembly is inserted through a 1 m diameter opening at the top of the chamber for each shot. Figure 1 illustrates how the RTL/target assembly couples to the chamber. Everything inside the shear line is replaced each shot. The present strategy for Z-IFE is to use high yield targets (2-3 GJ/shot), low repetition rate per chamber ( $0.1 \mathrm{~Hz})$, and 12 chambers per power plant (with 10 operating at any given time) to give a total power of $\sim 1$ GWe. Key issues for ZIFE include the design of the RTL/target assembly and automated insertion system and the design of a chamber that can withstand the blast and radiation effects from large yield targets.

The current RTL design calls for approximately $50 \mathrm{~kg}$ of iron to be molded into two concentric cones approximately $100 \mu$ m thick. Frozen molten salt (e.g., $2 \mathrm{LiF}^{-\mathrm{BeF}_{2}}$ or flibe) is also being considered. This study looks at the RTL material choice from a safety and environmental point of view. All naturally occurring elements with $3 \leq \mathrm{Z} \leq 84$ were assessed according to waste disposal rating (WDR) and contact dose rate (CDR). The WDR allows us to determine the suitability of shallow land burial after use [2], and the CDR allows us to calculate the dose to remote recycling equipment as the material is reformed into a new RTL for later shots.

The chamber vessel containing these shots must be able to withstand the blast and radiation damage for many years (ideally for the life of the power plant, assumed to be 30 years). A thick liquid wall chamber, that has a neutronically thick array of flowing molten salt jets between the target and chamber wall, is used to mitigate shock to the chamber structural walls. With on the order of one meter of liquid protection, the radiation damage rate can be reduced to the point that the chamber first wall could be a lifetime component.

Neutronics calculations using TART2002, a 3-D neutron-photon Monte-Carlo code from LLNL, were performed to evaluate the nuclear design issues for the RTL and Z-IFE chamber [3]. Section 2 describes chamber/RTL system, Section 3 presents results from the RTL analysis, Section 4 covers the radiation dose to the chamber wall, and Section 5 gives conclusions and recommendations.

\section{Description of System}


The Z-IFE power plant can be made up of several chambers to achieve the desired total plant output (typically 1 GWe). Previous studies suggested using 10 chambers each producing $300 \mathrm{MW}$ of fusion power (3 GJ and 0.1 $\mathrm{Hz}$ per chamber). While this is feasible and perhaps desirable from a development point of view, economies of scale will favor having a single chamber with the largest acceptable yield. This neutronics study is based on the single large chamber approach. Our proposed chamber geometry is a carbon-carbon composite cylindrical chamber with a $6 \mathrm{~m}$ radius and a height of $8 \mathrm{~m}$. This chamber is designed to take $20 \mathrm{GJ}$ yields and operate at $0.1 \mathrm{~Hz}$, for a fusion power of 2000 MW. As shown in Fig. 2, a flibe jet array is used to protect the chamber wall from damage. Segmenting the liquid protection region into many individual cylindrical jets is necessary to mitigate the blast shock produced by the fusion explosion. The jet array region is $\sim 3 \mathrm{~m}$ thick and has an average liquid fraction of $1 / 3$ giving an effective shielding of $1 \mathrm{~m}$. This is a preliminary configuration that gives very good radiation protection to the chamber wall. More analysis is needed, however, to calculate shock mitigation effectiveness as a function of the jet array thickness and configuration and to determine if yields as high as proposed here can be contained.

Figure 3 is a CAD sketch of a cutaway of the proposed chamber. The conical shaped RTF is seen protruding into the center region of the jet array. Note that there is a $2 \mathrm{~m}$ deep flibe pool at the bottom of the chamber. This pool is used to collect all of the flibe dropping from the top of the chamber and to protect the bottom of the chamber from direct target output directed downward.

Table 1 provides a description of the neutronics model for the chamber. With this configuration, our 3-D neutronics calculation gives a tritium breeding ratio of 1.08 and a total of $16.73 \mathrm{MeV}$ deposited per source neutron. Including the fusion alpha energy (3.52 MeV) gives $20.25 \mathrm{MeV}$ per fusion event. Therefore, the $2000 \mathrm{MW}$ of fusion power (20 GJ targets at $0.1 \mathrm{~Hz}$ ) results in a chamber thermal power of $2300 \mathrm{MW}$. With a power conversion efficiency of $50 \%$ or greater, which is possible with the high temperature structural material proposed for this design, the gross electric power of the plant will be 1.15 GWe.

\section{Recyclable Transmission Line (RTL) Analysis}

The recyclable transmission lines (RTLs) for the Z-pinch IFE power plant allow large amounts of power to be transmitted to the target during a shot. The RTL must be capable of transmitting 10-100 MA through two concentric conical sheets of conducting material. The RTL must also be structurally capable of being brought in for each shot 
by some type of crane or holding device. With vacuum between the inner and outer walls of the RTL and 10-20 torr in the chamber, stresses will be put on the RTL, and the thickness and rigidity of the RTL must be able to withstand the forces imparted to it without significant distortion.

The current baseline case for the RTL design is to use iron as the conducting material. Due to the required thickness ( 100 microns) and size, these RTLs are approximately $50 \mathrm{~kg}$. The material throughput is enormous and will require reprocessing even though the RTL material will be activated. Material choice for the RTL is very important from a safety and environmental perspective. Ideally, we want a material to be classified for shallow land burial (Class $\mathrm{C}$ waste). We also want the dose to remote handling equipment from activated RTL material to be low enough that the equipment lifetime is as long as the plant life.

Because of these requirements, a study of alternative RTL materials was performed. Each element on the periodic table was analyzed for waste disposal rating and contact dose rate to remote handling equipment. Note that for ease of comparison, constant volume was used for each element, as the shape of the RTL will be similar no matter what choice of material is made. The neutron spectrum for the RTL was generated using the TART2002 code. Using that neutron spectrum, each material was run through the ACAB activation code [4] using an automated process. Waste disposal rating data and contact dose rate information were extracted. We considered two scenarios: weekly and daily recycling. Weekly recycling would allow the material to cool in a holding area for seven days before being recycled and re-shot in the power plant. Daily recycling may be required if having seven days of cooling creates too much waste inventory. These two scenarios will most likely bound actual recycling scenarios. Waste disposal ratings of less than or equal to one are acceptable for shallow land burial. A contact dose rate less than or equal to $114 \mathrm{~Gy} /$ hour gives an acceptable lifetime dose to the machinery $<3 \cdot 10^{7} \mathrm{~Gy}$ in 30 years [5]. As expected, we found that many of the low atomic number elements are acceptable for our scenarios, but the higher atomic number elements would require significant engineering to be used. Results for several materials, including the two leading options iron and flibe, are summarized in Table 2.

Iron could be chosen as the RTL material from a safety and environmental point-of-view; however caution should be used with daily recycling, as the contact dose rate is very high and would cause damage to operating equipment. Materials such as a frozen flibe could also be considered, as their activation characteristics easily meet the acceptance criteria. Other selection criteria may, however, be even more important. For example, electrical 
conductivity is a key consideration in designing an RTL, as the power must be delivered to the target in a timely and efficient manner. We are merely presenting one important perspective in the RTL material selection process.

\section{Chamber Wall Issues}

Different materials can be considered for the first structural wall for the Z-pinch IFE power plant. As an advanced design case, we propose using a carbon composite wall that could be operated at higher temperatures than steel. An advanced Brayton cycle could then be used to get high thermal cycle efficiencies. The SOMBRERO study [6] looked at a carbon composite first wall for laser-driven inertial fusion energy. Liquid jets did not protect the wall in Sombrero, so the neutron damage rate was high, on the order of 15 dpa per full-power-year (fpy) of operation. After a few years (or less) swelling would require replacement of the first wall. Obviously, this is not attractive for a power plant, where plant availability is very important for the economics of the plant, and removing and replacing the chamber wall every few years could have a significant economic impact.

For this Z- IFE chamber using 1 meter of flibe for shielding, we find a carbon damage of $\sim 10$ dpa for the 30 full-power-year lifetime of the plant ( $0.3 \mathrm{dpa} / \mathrm{fpy})$. Carbon/carbon initially experiences densification under neutron radiation followed by rapid swelling. At $10 \mathrm{dpa}$, the material has compacted by $0.05 \%$, which can be accommodated by the design.

Due to the relative ease of calculation, the neutron dose to the carbon wall has been used as a figure of merit. Once the location with the highest dose was determined, the neutron spectrum within this zone was used to determine the dpa rate in that zone [7]. Figure 4 is a plot of the dose as a function of height from the bottom to top of the chamber wall. It is averaged over all azimuthal angles. At low heights the dose is very small, due to the flibe pool sitting at the bottom of the chamber attenuating the radiation. The peak dose rate $\left(\sim 5 \times 10^{8} \mathrm{~Gy} / \mathrm{y}\right)$ occurs near the target elevation of $6.12 \mathrm{~m}$. We also examined the dose azimuthally around the chamber and found that it is quite uniform, varying by less than $10 \%$.

X-ray and debris ablation of the surface of the innermost jets creates high-pressure plasma in the central pocket of the chamber that could cause significant acceleration of the flibe pocket into the wall. The shock from the blast must be adequately mitigated, and the gases must vent properly to allow the pressure near the target to drop. The 
current tightly packed jet configuration might inhibit venting. Therefore, we propose a possible solution by creating curved venting areas in our jet configuration, as shown in Fig. 5 below.

Including these venting channels should allow the high-pressure gas to be released from the area close to the target with less acceleration of the liquid toward the wall. This will have to be simulated to quantify the benefit, using a hydrodynamics code such as TSUNAMI [8]. However, with this new jet array the carbon wall will see a higher neutron dose than with the previous configuration. Since there are four vent channels, it is easier for the neutrons to impact the wall. Originally the dose was fairly uniform across all zones, which is to be expected with symmetric and uniform jet geometries. However, once the voids are put in place, the dose will rise due to neutron streaming. As shown in Fig. 6, it is obviously seen that the four venting channels create paths for the neutrons to impact the wall. The peak neutron dose at these points is $\sim 7 \times$ larger than for the symmetric, uniform jet case. If these dose levels prove to be a problem, a possible solution would be to put a final jet with a large diameter at the exit point of each of these void regions. This would decrease the neutron dose significantly, but still allow for better venting of the gases. The configuration of the jet array to provide good neutron shielding while allowing adequate venting so that the liquid impact on the wall is tolerable is an important design issue that needs more work. An alternative approach would be to time the shot to occur before the jets reach the bottom pool (pulsed injection of the jets rather than steady flow is currently envisioned), thus allowing a venting gap at the bottom of the jet array [9].

\section{Conclusions and Recommendations}

Preliminary neutronics calculations and analyses have been performed for the proposed Z-IFE chamber that uses a thick-liquid-wall protection and a carbon composite first wall. Analyses of the recyclable transmission lines (RTLs) were completed due to the requirement that the RTL materials must be recycled in order to control the amount of activated waste. A neutronics analysis was performed for each element in the periodic table to look for candidate materials that may outperform the current baseline selection for the RTL, iron. Waste disposal ratings and contact dose rates to remote handling equipment were determined for the elements. It was found that iron was an acceptable material when looking at these two tests, however there were also other materials that performed very well. Frozen flibe, if power transmission can be handled, would be a very attractive candidate for the RTLs, as separation from the protecting flibe pocket would not be necessary, and the waste disposal rating and the contact 
dose rates are very low compared with other materials. (Note that it is the conductivity of flibe plasma that matters for use in the RTL, not the conductivity of solid flibe.) Our recommendation is to continue with iron as the baseline material for the RTL but have a parallel effort to evaluate the feasibility of using frozen flibe RTLs.

Containing high yield targets in a compact fusion chamber requires shock mitigation and a very robust wall. To minimize chamber maintenance and improve economics, it is desirable to have the chamber wall last the entire lifetime of the power plant. A thick-liquid-wall chamber can meet these objectives. The Z-IFE chamber using a segmented jet array was modeled and radiation dose to the chamber wall calculated. Using these doses, we estimate a total displacement damage of only 10 dpa over 30 full power years. Therefore, it should be possible to design a first wall that lasts for the life of the plant, at least from a radiation damage standpoint. We recommend the use of a carbon-carbon composite chamber wall, as it would allow for higher chamber temperatures, and therefore higher thermal efficiencies from the power conversion system. Finally, we note that the move to a single chamber will provide economic benefits as long as the economy of scale wins out over a possible loss in plant availability when something happens in the single chamber.

\section{References}

[1] C.L. Olson et al., Development path for Z-pinch IFE, $16^{\text {th }}$ Technology of Fusion Energy Conference (Madison, WI, Sept. 14-16 2004), to be published in Fusion Science and Technology.

[2] S. Fetter, E.T. Cheng and E.M. Mann, Long-term radioactive waste from fusion reactors: Part II, Fusion Engineering and Design, 13, 239 (1990).

[3] D.E. Cullen, TART98: A coupled neutron photon, 3-D, combinatorial geometry, time dependent, Monte Carlo transport code, UCRL-ID-126455, Rev. 2, Lawrence Livermore National Laboratory (1998).

[4] J. Sanz, ACAB98: Activation code for fusion applications. User's Manual V4.0, UCRL-CR-133040, Universidad Nacional de Educacion a Distancia (UNED) and Lawrence Livermore National Laboratory (1999).

[5] J.F. Latkowski et al., Selection of IFE target materials from a safety and environmental perspective, Nucl. Inst. and Meth. A., 464, 422-427 (2001).

[6] W.R. Meier, Osiris and Sombrero Inertial fusion power plant designs - summary, conclusions, and recommendations, Fusion Eng. and Design, 25, 145-157 (1994).

[7] A. Rodríguez, J. Sanz, Multigroup damage energy and dpa cross sections for coupling transmutant and displacement damage calculations using the ACAB code, Universidad Nacional de Educación a Distancia, Departamento de Ingeniería Energética, Ingeniería Nuclear, UNED/DIE-IN 18 (March 2003).

[8] C.S. Debonnel et al., Visual Tsunami: A versatile, user-friendly radiation hydrodynamics design code, $16^{\text {th }}$ Technology of Fusion Energy Conference (Madison, WI, Sept. 14-16 2004), to be published in Fusion Science and Technology.

[9] P.F. Peterson, personal communication (Aug. 2004). 
Table 1. Description of Neutronics Model.

\begin{tabular}{|c|c|}
\hline \multicolumn{2}{|l|}{ Chamber } \\
\hline Material & carbon \\
\hline Inner radius & $6.0 \mathrm{~m}$ \\
\hline Thickness & $0.1 \mathrm{~m}$ \\
\hline $\begin{array}{l}\text { Height (bottom of pool to } \\
\text { top of inlet region) }\end{array}$ & $10.0 \mathrm{~m}$ \\
\hline \multicolumn{2}{|l|}{ Jet Array } \\
\hline Material & flibe \\
\hline Inner radius & $1.0 \mathrm{~m}$ \\
\hline Outer radius & $4.0 \mathrm{~m}$ \\
\hline Liquid fraction & 0.33 \\
\hline \multicolumn{2}{|l|}{ Bottom Pool } \\
\hline Material & flibe \\
\hline Distance from target & $4.12 \mathrm{~m}$ \\
\hline Depth & $2.00 \mathrm{~m}$ \\
\hline \multicolumn{2}{|l|}{ Top Inlet Region } \\
\hline Material & flibe \\
\hline Distance from target & $1.88 \mathrm{~m}$ \\
\hline Thickness & $2.00 \mathrm{~m}$ \\
\hline \multicolumn{2}{|l|}{ Target Insertion Assembly } \\
\hline \multicolumn{2}{|l|}{ Conical shape } \\
\hline Material & flibe \\
\hline Height & $1.88 \mathrm{~m}$ \\
\hline Radius at top & $0.50 \mathrm{~m}$ \\
\hline Half angle & 15 degrees \\
\hline \multicolumn{2}{|l|}{ Target } \\
\hline Material & DT \\
\hline$\rho \mathrm{R}$ & $3 \mathrm{~g} / \mathrm{cm}^{2}$ \\
\hline Distance from bottom of pool & $6.12 \mathrm{~m}$ \\
\hline
\end{tabular}


Table 2. Contact Dose Rate (Gy/h) and Waste Disposal Rating (unitless) for 30 years of operation with various materials when used in RTL with 1 or 7 days between shots.

\begin{tabular}{|l|c|c|c|c|}
\hline & \multicolumn{2}{|c|}{1 day } & \multicolumn{2}{c|}{7 days } \\
\hline & $\mathrm{CDR}$ & WDR & CDR & WDR \\
\hline $\mathrm{Li}$ & $0^{*}$ & 0 & 0 & 0 \\
\hline $\mathrm{Be}$ & 0 & $5.1 \mathrm{E}-5$ & 0 & 0 \\
\hline $\mathrm{F}$ & 0 & $6.7 \mathrm{E}-3$ & 0 & 0 \\
\hline $\mathrm{Al}$ & $2.4 \mathrm{E} 7$ & 75 & 0.40 & 0.15 \\
\hline $\mathrm{Fe}$ & $5.7 \mathrm{E} 4$ & $7.3 \mathrm{E}-5$ & 2.9 & 0 \\
\hline $\mathrm{Ti}$ & $6.8 \mathrm{E} 6$ & $2.1 \mathrm{E}-3$ & 9.8 & 0 \\
\hline $\mathrm{V}$ & $1.9 \mathrm{E} 6$ & 0 & 0.93 & 0 \\
\hline $\mathrm{Ni}$ & $1.7 \mathrm{E} 6$ & 1.3 & 47 & $2.6 \mathrm{E}-3$ \\
\hline $\mathrm{Cu}$ & $5.9 \mathrm{E} 4$ & 1.1 & 6.4 & $1.9 \mathrm{E}-3$ \\
\hline $\mathrm{Sn}$ & $6.7 \mathrm{E} 4$ & 0.57 & 0.44 & $5.7 \mathrm{E}-4$ \\
\hline $\mathrm{Pb}$ & $9.3 \mathrm{E} 3$ & 2.5 & $6.1 \mathrm{E}-3$ & $1.1 \mathrm{E}-6$ \\
\hline
\end{tabular}

Zeros include results $<10^{-6}$ 


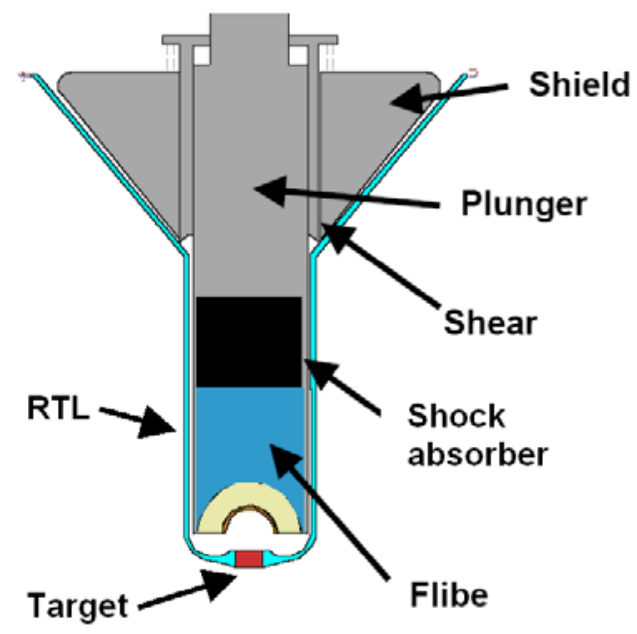

Fig.1. Schematic of RTL/target assembly. (The shape of the RTL may be more conical than cylindrical as in this illustration.) 


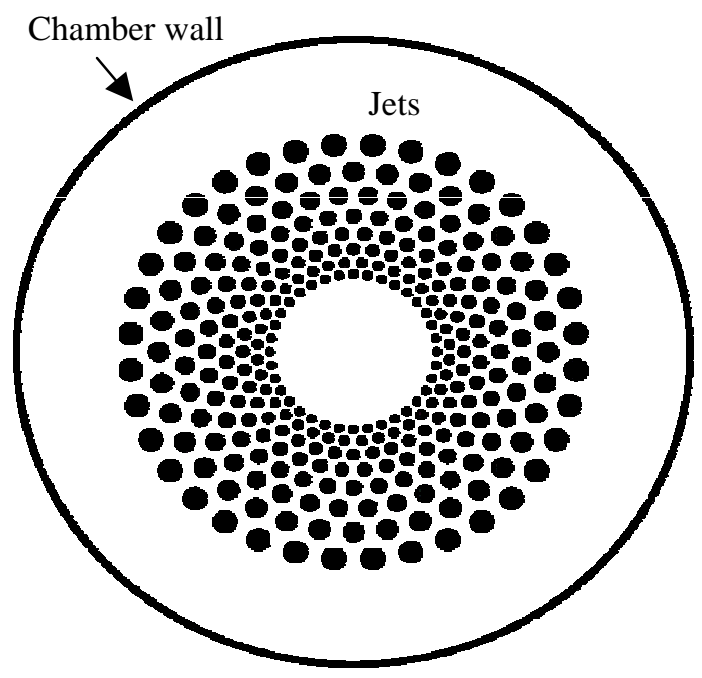

Fig. 2. Flibe jet geometry (horizontal cut at target plane). The 3-m thick jet area has a packing fraction of 1/3 giving an equivalent of $1 \mathrm{~m}$ of shielding. 


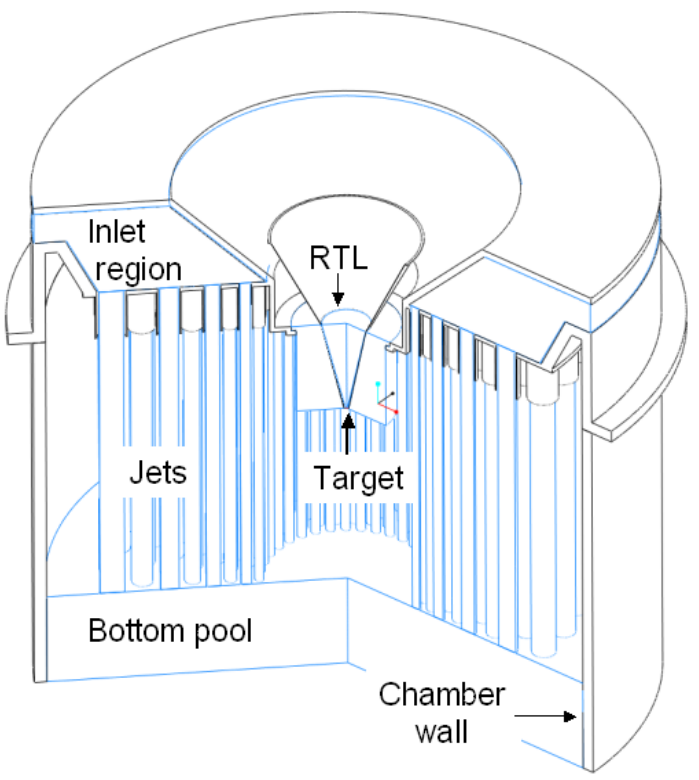

Fig. 3. Cut-away view of the Z-IFE chamber with flibe jet geometry. 


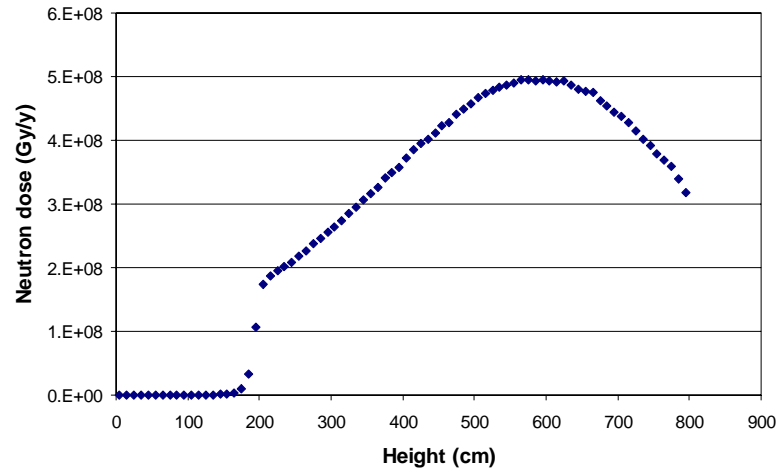

Fig. 4. Graph of neutron dose (Gy/y) versus the vertical position on the chamber wall (measured from bottom of pool). Notice that the peak dose occurs near the target plane (at $612 \mathrm{~cm}$ ). 


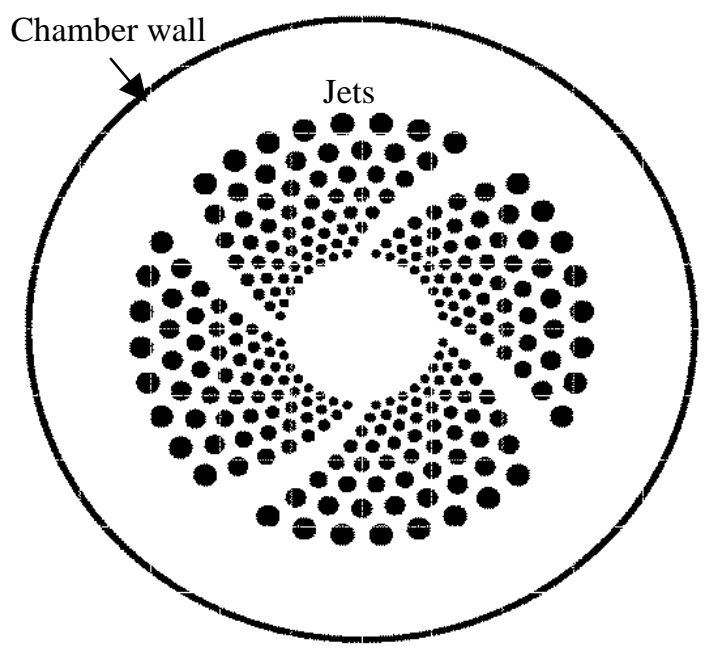

Fig. 5. A proposed method to allow the gases to escape the center area of the chamber during the blast. The curvature of the voids prevents direct line of sight from the target to the wall, yet still allows the gases to vent. 


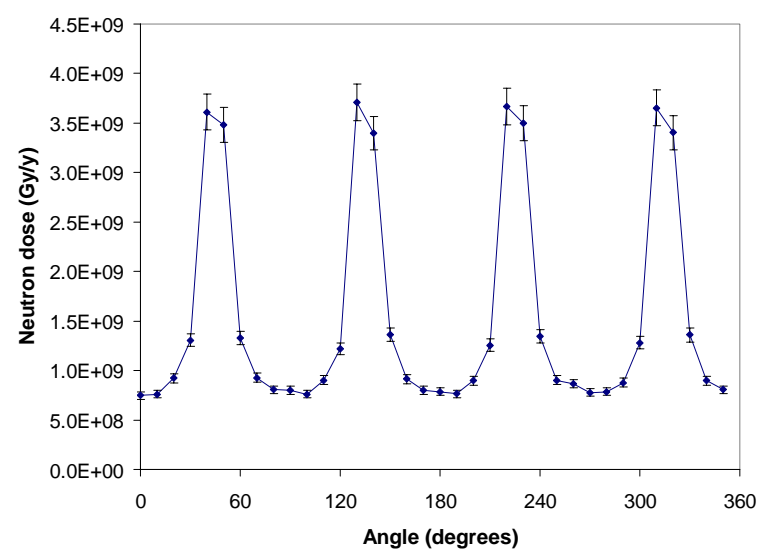

Fig. 6. Neutron dose (Gy/y) versus angle around the chamber for the configuration shown in Fig. 5. Note the peaks due to the four venting channels. 